Pacific Journal of Mathematics

ON EXTREMELY REGULAR FUNCTION SPACES 


\section{ON EXTREMELY REGULAR FUNCTION SPACES}

\section{Bahattin Cengiz}

In this paper extremely regular function spaces are defined and discussed. A necessary and sufficient condition for the existence of proper extremely regular linear subspaces of $C_{0}(X)$ is obtained.

If $X$ is a locally compact space ${ }^{1}$, we denote by $C_{0}(X)$ the Banach space of continuous, complex-valued functions vanishing at infinity on $X$, provided with the usual supremum norm.

We call a closed linear subspace $A$ of $C_{0}(X)$ extremely regular (over $X$ ), if for each $x_{0} \in X$ and each neighborhood $V$ of $x_{0}$ and each $0<\varepsilon<1$ there is a function $f$ in $A$ such that

$$
1=\|f\|=f\left(x_{0}\right)>\varepsilon>|f(x)| \text { for every } x \in X \backslash V \text {. }
$$

If $\varepsilon$ can be replaced by zero in the above definition, that is,

$$
1=\|f\|=f\left(x_{0}\right)>f(x)=0 \text { for every } x \in X \backslash V,
$$

we call $A$ extremely regular of type zero.

If for each $x_{0} \in X$, each open neighborhood $V$ of $x_{0}$ there is a function $f \in A$ such that

$$
1=\|f\|=f\left(x_{0}\right)>\sup \{|f(x)|: x \in X \backslash V\}
$$

then we call $A$ completely regular.

Myers [3] has proved that a sufficient condition for compact spaces $X$ and $Y$ to be homeomorphic is that a completely regular linear subspace of $C^{r}(X)$ and such a subspace of $C^{r}(Y)$ be isometrically isomorphic, where $C^{r}(X)$ (resp. $C^{r}(Y)$ ) denotes the real-valued continuous functions on $X$ (resp. $Y$ ).

Cambern [1] has shown that if $\phi$ is a linear isomorphism of $C_{0}(X)$ onto $C_{0}(Y)$, for any locally compact spaces $X$ and $Y$, with $\|\phi\| \cdot\left\|\phi^{-1}\right\|<2$, then $X$ and $Y$ are homeomorphic.

In [2], we have shown that in certain special cases the above mentioned generalizations of the well-known Banach-Stone theorem can be combined. More precisely, if $\phi$ is a linear isomorphism of an extremely regular subspace of $C_{0}(X)$ onto such a subspace of $C_{0}(Y)$ with $\|\phi\| \cdot\left\|\phi^{-1}\right\|<2$, then $X$ and $Y$ are homeomorphic.

This result suggests that we should know more about the extremely regular function spaces. It is clear that every proper extremely regular function space is contained in a maximal one.

\footnotetext{
1 Throughout this paper all topological spaces will be Hausdorff.
} 
The main purpose of this article is to prove the following:

Theorem. Let $X$ be a locally compact space and let $M_{c}(X)$ denote the set of all nonzero, continuous, complex-valued finite regular Borel measures on $X$. For each $\mu \in M_{c}(X)$, let $K(\mu)$ denote the kernel of $\mu$ in $C_{0}(X)$. Then,

(a) For each $\mu \in M_{c}(X), K(\mu)$ is a maximal extremely regular linear subspace of $C_{0}(X)$ of type zero.

(b) If $A$ is a maximal extremely regular linear subspace of $C_{0}(X)$, then $A=K(\mu)$ for some $\mu \in M_{c}(X)$.

(c) $C_{0}(X)$ has no proper extremely regular linear subspace if, and only if, $X$ is dispersed (i.e. the $\alpha$ th derived set of $X$ is void for some ordinal number $\alpha$ ).

Before beginning the proof of the theorem, we wish to establish some conventions concerning notation. For a finite regular Borel measure $\mu$ on a locally compact space $X$ we denote $\int_{X} f d \mu$ by $\mu(f)$, $f \in C_{0}(X)$, and $|\mu|(X)$ by $\|\mu\|$, where $|\mu|$ denotes the total variation of $\mu$. For a point $x \in X, \mu_{x}$ denotes the unit point mass at $x$.

Proposition. Let $\mu$ be a finite regular Borel measure on a locally compact space $X$ such that $K(\mu)$ contains an extremely regular linear subspace of $C_{0}(X)$. Then, $\mu$ is continuous, that is, the atomic part of $\mu$ is zero.

Proof. Let $A$ be an extremely regular linear subspace of $C_{0}(X)$ contained in $K(\mu)$, and suppose that $\mu$ is not continuous. Then, there is a finite (with at least two points) or countably infinite subset $F=\left\{x_{1}, x_{2}, \cdots\right\}$ of $X$ such that

$$
\mu=\sum_{i} \alpha_{i} \mu_{x_{i}}+\nu
$$

where $\alpha_{i}$ are nonzero constants, and where $\nu$ is the continuous part of $\mu$.

Let $\varepsilon$ be any number with $0<\varepsilon<1$, and let $m$ be a positive integer which is either the number of points in $F$ or such that

$$
\sum_{i=m+1}^{\infty}\left|\alpha_{i}\right|<\varepsilon
$$

according as $F$ is finite or infinite.

Let $V$ be any open neighborhood of $x_{1}$ that contains none of the points $x_{2}, \cdots, x_{m}$ and that $|\nu|(V)<\varepsilon$. Now, choose an element $f$ of $A$ with

$$
1=\|f\|=f\left(x_{1}\right)>\varepsilon \geqq|f(x)| \text { for all } x \text { in } X \backslash V \text {. }
$$


From

$$
0=\mu(f)=\alpha_{1}+\sum_{i \geq 2} \alpha_{i} f\left(x_{i}\right)+\nu(f)
$$

we obtain

$$
\left|\alpha_{1}\right|<\varepsilon(\|\mu\|+2) \text {. }
$$

From this inequality it follows that $\alpha_{1}=0$, and this contradiction completes the proof.

Proof of the theorem. (b) follows from the Hahn-Banach and Riesz representation theorems and the above proposition. (c) follows from the above proposition and the fact that $X$ is dispersed if, and only if, $M_{c}(X)=\varnothing$. (Cf. Pelczynski-Semadeni [4].)

For Part (a), we shall first show that for each $\mu \in M_{c}(X), x_{0} \in X$ there exists $f \in C_{0}(X)$ with $1=\|f\|=f\left(x_{0}\right)$ and $\mu(f)=0$.

Let $V$ be a compact neighborhood of $x_{0}$. We may assume that the restriction of $\mu$ to $X \backslash V$ is not zero. Then, it follows that there exists a function $g$ in $C_{0}(X)$ such that $1=\|g\|, g(x)=0$ for all $x \in V$ and that $\mu(g) \neq 0$. Now choose a function $h$ in $C_{0}(X)$ with $1=\|h\|=h\left(x_{0}\right), h(x)=0$ for each $x \in X \backslash V$ and $|\mu(h)| \leqq|\mu(g)|$. Clearly, the function $f=h+\alpha g$, where $\alpha=-\mu(h) / \mu(g)$, satisfies the above requirements.

Now, to complete the proof of Part (a) (thus, that of the theorem) take any open neighborhood $U$ of $x_{0}$. Then by the above result ( $X$ and $\mu$ replaced by $U$ and the restriction of $\mu$ to $U$ respectively) there exists a function $f$ in $C_{0}(X)$ such that $\mu(f)=0$ and that $1=\|f\|=$ $f\left(x_{0}\right)>f(x)=0$ for all $x \in X \backslash U$.

REMARK 1. A proper extremely regular linear subspace of $C_{0}(X)$ of type zero need not be maximal. (Let $X$ denote the closed unit interval $[0,1]$ and $m$ denote the Lebesgue measure on $X$ and let $m^{\prime}$ be such that $m^{\prime}(B)=m(B \cap[0,1 / 2])$, for every Borel set $B$ in $X$. Consider $K(m) \cap K\left(m^{\prime}\right)$.)

REMARK 2. An extremely regular linear subspace of $C_{0}(X)$ need not be of type zero. An example of this kind can be obtained by restricting the functions which are continuous on the closed unit disc and analytic inside to the unit circle in the Euclidean plane.

REMARK 3. Every extremely regular function space is completely regular. But the converse is not true, since it can be shown that if $X$ is a locally compact space with at least three points, $C_{0}(X)$ has closed completely regular proper linear subspaces. (This fact is clear 
if $X$ is non-dispersed. If $X$ is dispersed, it has at least three isolated points, $x, y$, and $z$, say. Consider $K(\mu)$, where $\mu=\mu_{x}+\mu_{y}+\mu_{z}$.)

\section{REFERENCES}

1. M. Cambern, On isomorphisms with small bound, Proc. Amer. Math. Soc., 18 (1967), $1062-1066$.

2. B. Cengiz, A generalization of the Banach-Stone theorem, to appear in the Proc. Amer. Math. Soc.

3. S. B. Myers, Banach spaces of continuous functions, Annals of Math., 49 (1948), 132-140.

4. A. Pelczynski and Z. Semadeni, Spaces of continuous functions (III), Studia Math. T. XVII, (1959), 211-222.

Received April 18, 1972 and in revised form May 1, 1973. Work supported by Scientific and Technical Research Council of Turkey.

Middle East Technical University

ANKARA, TURKEY 


\section{PACIFIC JOURNAL OF MATHEMATICS}

\section{EDITORS}

RICHARD ARENS (Managing Editor)

University of California

Los Angeles, California 90024

\section{R. A. Beaumont}

University of Washington

Seattle, Washington 98105

\section{J. DuGundJI*}

Department of Mathematics

University of Southern California

Los Angeles, California 90007

D. Gilbarg and J. Milgram

Stanford University

Stanford, California 94305

ASSOCIATE EDITORS
E. F. BECKENBACH
B. H. NeumanN
F. WOLF
K. YoSHIDA

\section{SUPPORTING INSTITUTIONS}

UNIVERSITY OF BRITISH COLUMBIA

CALIFORNIA INSTITUTE OF TECHNOLOGY

UNIVERSITY OF CALIFORNIA

MONTANA STATE UNIVERSITY

UNIVERSITY OF NEVADA

NEW MEXICO STATE UNIVERSITY

OREGON STATE UNIVERSITY

UNIVERSITY OF OREGON

OSAKA UNIVERSITY

\author{
UNIVERSITY OF SOUTHERN CALIFORNIA \\ STANFORD UNIVERSITY \\ UNIVERSITY OF TOKYO \\ UNIVERSITY OF UTAH \\ WASHINGTON STATE UNIVERSITY \\ UNIVERSITY OF WASHINGTON \\ AMERICAN MATHEMATICAL SOCIETY \\ NAVAL WEAPONS CENTER
}

The Supporting Institutions listed above contribute to the cost of publication of this Journal, but they are not owners or publishers and have no responsibility for its content or policies.

Mathematical papers intended for publication in the Pacific Journal of Mathematics should be in typed form or offset-reproduced, (not dittoed), double spaced with large margins. Underline Greek letters in red, German in green, and script in blue. The first paragraph or two must be capable of being used separately as a synopsis of the entire paper. Items of the bibliography should not be cited there unless absolutely necessary, in which case they must be identified by author and Journal, rather than by item number. Manuscripts, in duplicate if possible, may be sent to any one of the four editors. Please classify according to the scheme of Math. Rev. Index to Vol. 39. All other communications to the editors should be addressed to the managing editor, or Elaine Barth, University of California, Los Angeles, California, 90024.

50 reprints are provided free for each article; additional copies may be obtained at cost in multiples of 50 .

The Pacific Journal of Mathematics is issued monthly as of January 1966. Regular subscription rate: $\$ 48.00$ a year (6 Vols., 12 issues). Special rate: $\$ 24.00$ a year to individual members of supporting institutions.

Subscriptions, orders for back numbers, and changes of address should be sent to Pacific Journal of Mathematics, 103 Highland Boulevard, Berkeley, California, 94708.

\section{PUBLISHED BY PACIFIC JOURNAL OF MATHEMATICS, A NON-PROFIT CORPORATION}

Printed at Kokusai Bunken Insatsusha (International Academic Printing Co., Ltd.), 270, 3-chome Totsuka-cho, Shinjuku-ku, Tokyo 160, Japan.

* C. R. DePrima California Institute of Technology, Pasadena, CA 91109, will replace J. Dugundji until August 1974.

Copyright (C) 1973 by

Pacific Journal of Mathematics

All Rights Reserved 


\section{Pacific Journal of Mathematics}

\section{Vol. 49, No. $2 \quad$ June, 1973}

Wm. R. Allaway, On finding the distribution function for an orthogonal polynomial

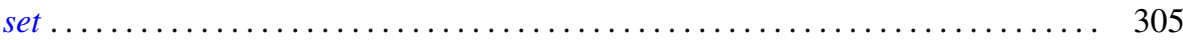

Eric Amar, Sur un théorème de Mooney relatif aux fonctions analytiques bornées... . 311

Robert Morgan Brooks, Analytic structure in the spectrum of a natural system . . . . 315

Bahattin Cengiz, On extremely regular function spaces . . . . . . . . . . . . . . 335

Kwang-nan Chow and Moses Glasner, Atoms on the Royden boundary . . . . . . . . . 339

Paul Frazier Duvall, Jr. and Jim Maxwell, Tame $Z^{2}$-actions on $E^{n} \ldots \ldots \ldots \ldots \ldots . .349$

Allen Roy Freedman, On the additivity theorem for $n$-dimensional asymptotic

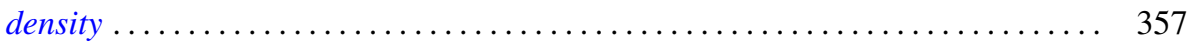

John Griffin and Kelly Denis McKennon, Multipliers and the group $L_{p}$-algebras . . . 365

Charles Lemuel Hagopian, Characterizations of $\lambda$ connected plane continua ....... 371

Jon Craig Helton, Bounds for products of interval functions . . . . . . . . . . . 377

Ikuko Kayashima, On relations between Nörlund and Riesz means . . . . . . . . . . 391

Everett Lee Lady, Slender rings and modules . . . . . . . . . . . . . . . . . . 397

Shozo Matsuura, On the Lu Qi-Keng conjecture and the Bergman representative

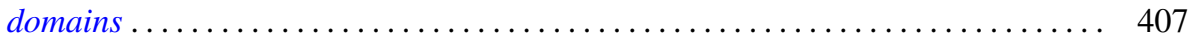

Stephen H. McCleary, The lattice-ordered group of automorphisms of an $\alpha$-set . . . 417

Stephen H. McCleary, o-2-transitive ordered permutation groups .......... 425

Stephen H. McCleary, o-primitive ordered permutation groups. II . . . . . . . . . 431

Richard Rochberg, Almost isometries of Banach spaces and moduli of planar

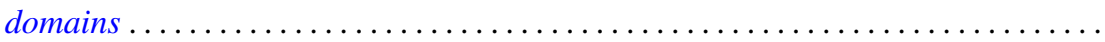

R. F. Rossa, Radical properties involving one-sided ideals . . . . . . . . . . . . . 467

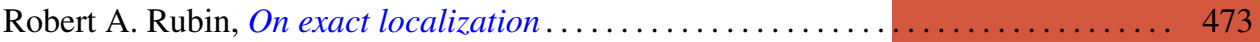

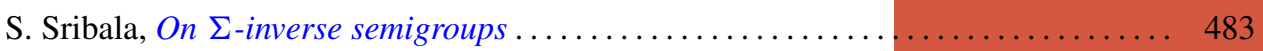

H. M. (Hari Mohan) Srivastava, On the Konhauser sets of biorthogonal polynomials suggested by the Laguerre polynomials ...................... 489

Stuart A. Steinberg, Rings of quotients of rings without nilpotent elements . ...... 493

Daniel Mullane Sunday, The self-equivalences of an $H$-space . . ............ 507

W. J. Thron and Richard Hawks Warren, On the lattice of proximities of $\check{C} e c h$

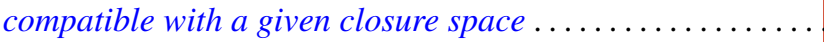

Frank Uhlig, The number of vectors jointly annihilated by two real quadratic forms determines the inertia of matrices in the associated pencil .

Frank Uhlig, On the maximal number of linearly independent real vectors annihilated simultaneously by two real quadratic forms ..............

Frank Uhlig, Definite and semidefinite matrices in a real symmetric matrix pencil . . 561

Arnold Lewis Villone, Self-adjoint extensions of symmetric differential operators . . . 569

Cary Webb, Tensor and direct products . ....................... 579

James Victor Whittaker, On normal subgroups of differentiable

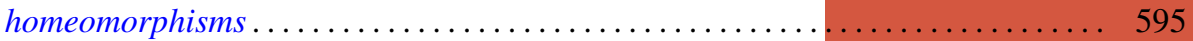

Jerome L. Paul, Addendum to: "Sequences of homeomorphisms which converge to

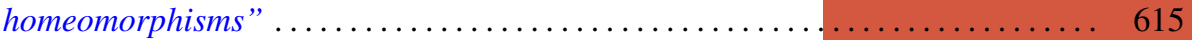

David E. Fields, Correction to: “Dimension theory in power series rings” ........ 616

Peter Michael Curran, Correction to: “Cohomology of finitely presented groups”. . . 617

Billy E. Rhoades, Correction to: “Commutants of some Hausdorff matrices” ...... 617

Charles W. Trigg, Corrections to: "Versum sequences in the binary system” ...... 619 